Reprod. Immunol. Biol. 20(1): 13-17.

JSIR Sympodium

\title{
Vitrification for embryo and oocyte freezing
}

\author{
Hidekazu Saito \\ Division of Reproductive Medicine, Department of Perinatal Medicine and Maternal Care, \\ National Center for Child Health and Development \\ 2-10-1 Okura, Setagaya-ku, Tokyo, 157-8535, Japan
}

In vitro fertilization and embryo transfer (IVF-ET) techniques have improved and more pregnancies have been established associated with higher rates of multiple pregnancies. Multiple pregnancies are associated with various obstetric complications including threatened abortion, threatened premature delivery, fetal malformation, necessity of cervical ligation and caesarean section, increased uterine bleeding at birth, and low birth weight babies. To prevent multiple pregnancies, one of the best approaches is to decrease the number of embryos transferred into the uterus. Consequently, several embryos are left to be cryopreserved for future embryo transfer.

Since Whittingham [1] first succeeded in freezing and thawing mouse embryos, different cryoprotectants, and freezing and thawing techniques have been investigated to improve the method. According to Whittingham's freezing system, 2 to 3 hours in the cryoprotectant are necessary for embryos to be frozen with minimal ice formation in the blastomeres. To avoid the lethal effects of ice formation, Luyte drew attention to the feasibility of using vitrification to cryopreserve biological materials [2]. Rall and Fahy [3] applied the vitrification method to cryopreserve mouse embryos using dimethyl sulfoxide (DMSO), acetamide, propylene glycol and polyethylene glycol. Unfortunately, when embryos were exposed for a long time at room temperature, they were adversely affected by the cryoprotectant at the concentration needed to vitrify embryos. Therefore, to achieve adequate vitrification, it was necessary a very short period of time to equilibrate embryo with the cryoprotectant. As the initial vitrification solutions were very toxic [3] to embryos, it was essential to formulate nontoxic and more efficient solutions for vitrification. Kasai developed a less toxic cryoprotectant composed of modified phosphate buffer solution (PBS), ethylene glycol, ficoll and sucrose [4]. He showed that the optimal equilibration time in the vitrification solution before rapid cooling varied with the ambient temperature when using the rate of blastocyst formation as a criterion [5]. Since then, other investigators developed more effective modern solutions that contained nonpenetrating additives [6-11], and various vitrification methods have been used for freezing human embryos [12-14]. Vitrification is a short and simple procedure that may be safer and more cost effective than slow cooling for embryo freezing. Kuleshova et al. compared the advantages and disadvantages of slow cooling and vitrification. Their results are shown in Table 1 [15].

Generally, the ultrastructure of oocytes is particularly sensitive to temperature and extracellular osmotic pressure changes during freezing and thawing. Various types of cellular damage are observed during oocyte freezing [16-18]. However, a reasonable number of deliveries have been achieved with the use of vitrified oocytes (Table 2). Although vitrification is still in its early stage of development, it may be more suitable for human oocyte cryopreservation than slow freezing due to its simplicity and 
Table 1. Comparison of vitrification and slow-cooling procedures [15]

\begin{tabular}{lcc}
\hline & Vitrification & Slow cooling \\
\hline Control of solute penetration & yes & no \\
$\begin{array}{l}\text { Control of dehydration rate } \\
\text { Maintenance of physiological temperature } \\
\text { during equilibration procedure }\end{array}$ & yes & no \\
$\begin{array}{l}\text { Duration of time out of incubator } \\
\text { Prolonged temperature shock }\end{array}$ & $\sim 10$ min \\
Capture by growing ice crystals & no & $\sim 3 \mathrm{~h}$ \\
Equipment and running costs & no & yes \\
\hline
\end{tabular}

Table 2. Delivery using vitrification for oocyte preservation

\begin{tabular}{ccl}
\hline Authors & Year & \multicolumn{1}{c}{ CPA and materials } \\
\hline $\begin{array}{c}\text { Kuleshova } \\
\text { et al [19] }\end{array}$ & 1999 & $\begin{array}{l}\text { EG/ sucrose/ open } \\
\text { pulled straw }\end{array}$ \\
Yoon et al [20] & 2000 & EG/ sucrose/EM grid \\
Yoon et al [21] & 2003 & EG/ sucrose/EM grid \\
\hline
\end{tabular}

CAP: cryoprotective agent, EG: ethylene glycol,

EM: electron microscopy.

capacity to prevent intracellular ice formation. To avoid the formation of intracellular ice, it is necessary to use a high concentration of cryoprotectant and an extremely rapid cooling speed.

Although vitrification has many advantages and has been successfully used for oocyte cryopreservation [19-21], its clinical outcome is still limited. Vitrification results in lower pregnancy and implantation rates in comparison to conventional embryo freezing techniques due to more severe damage caused to oocytes. To improve the quality of oocytes after vitrification, several methods for oocyte cryopreservation have been investigated.

A variety of different types of cryocontainers including electron microscopy grid [22], open pulled straws [23], and cryoloop [24] were developed, thus improving the successful vitrification rate of human oocytes and embryos.

Since cytoskeletal damage occurs during the vitrification procedure, it is necessary to stabilize the cytoskeletal system. Cytoskeletal stabilizers such as Taxol [25] or cytocharacine B [26] have been used in animal models with good results. However, in order to apply the same method to human oocytes, it is necessary to ascertain the safety of these compounds not only to the post-thaw intracellular cytoskeletal system but also to its postnatal development.

The use of high-speed cooling rate by slush liquid nitrogen (LN) may improve the results of oocyte vitrification. Slush LN offers high speed cooling rate and consequently maintains oocyte quality during the procedure [27].

Another way of improving vitrification is using a sodium-depleted cryoprotectant medium [28]. A sodium-depleted environment prevents the accumulation of excessive intracellular sodium that can induce cell death during thawing. To obtain a sodium-depleted medium it is necessary to add choline. Choline may directly stabilize cell membrane and protect it from the freezing damage.

Takahashi et al [29] examined the survival rate of mouse oocytes exposed to vitrification solutions containing various concentrations of ethylene glycol (EG) in relation to the changes in the intracellular calcium concentration. They found that $83 \%$ of the oocytes survived a 5 
Table 3. Suurvival rates of mouse oocytes exposed to vitrification solutions containing various concentrations of EG [29]

\begin{tabular}{cccccc}
\hline & & \multicolumn{4}{c}{ Number of intact oocytes $^{* *}$} \\
\cline { 3 - 5 } Vitrification solution & $\begin{array}{c}\text { Number of } \\
\text { oocytes }\left(\mathrm{n}^{*}\right)\end{array}$ & \multicolumn{4}{l}{ Time after exposure to EG } \\
\cline { 3 - 5 } & & $1 \mathrm{~min}$ & $2 \mathrm{~min}$ & $3 \mathrm{~min}$ & 5 min \\
\hline $0 \%$ EG (control) & $47(3)$ & $47(100)^{\mathrm{a}}$ & $47(100)^{\mathrm{a}}$ & $47(100)^{\mathrm{a}}$ & $47(100)^{\mathrm{a}}$ \\
$0 \% \mathrm{EG}+\mathrm{FT}$ & $26(3)$ & $26(100)^{\mathrm{a}}$ & $26(100)^{\mathrm{a}}$ & $26(100)^{\mathrm{a}}$ & $26(100)^{\mathrm{a}}$ \\
$10 \% \mathrm{EG}+\mathrm{FT}$ & $23(3)$ & $23(100)^{\mathrm{a}}$ & $23(100)^{\mathrm{a}}$ & $22(96)^{\mathrm{a}}$ & $22(96)^{\mathrm{a}}$ \\
$20 \% \mathrm{EG}+\mathrm{FT}$ & $31(3)$ & $31(100)^{\mathrm{a}}$ & $31(100)^{\mathrm{a}}$ & $30(97)^{\mathrm{a}}$ & $30(97)^{\mathrm{a}}$ \\
$40 \% \mathrm{EG}+\mathrm{FT}$ & $42(3)$ & $33(100)^{\mathrm{b}}$ & $33(100)^{\mathrm{a}}$ & $25(83)^{\mathrm{b}}$ & $25(83)^{\mathrm{b}}$ \\
\hline
\end{tabular}

FT: ficoll + trehalose.

Values with different superscript letters within the same column differ significantly. $\mathrm{P}<0.05$.

* Number of replicates.

${ }^{* *}$ percentage in parenthesis.

minutes exposure with 40\% EG + ficoll + trehalose. This result implies that nonpermeable cryoprotectants such as ficoll and trehalose contribute to the survival of oocytes during their exposure to the cryoprotectant (Table 3).

Although more reliable and safe oocyte vitrification methods are still necessary to be developed, this technique seems to be effective to preserve human oocytes.

\section{References}

1) Whittingham DG. 1971. Survival of mouse embryos after freezing and thawing. Nature 233: 125-126.

2) Luyet BJ. 1937. The vitrification of organic colloids and of protoplasm. Biodynamica 29: 1-14.

3) Rall WF, Fahy GM. 1985. Ice free cryopreservation of mouse embryos at $-196^{\circ} \mathrm{C}$ by vitrification. Nature 313 : 573-575.

4) Kasai $M$, Komi JH, Takakamo A, Tsudera H, Sakurai T, Machida T. 1990. A simple method for mouse embryo cryopreservation in a low toxicity vitrification solution without appreciable loss of viability. J Reprod Fertil 89: 91-97.

5) Kasai,M, Nishimori M, Zhu SE, Sakurai T, Machida T. 1992. Survival of mouse morulae vitrified in an Ethylene Glycol-based solution after exposure to the solution at various temperatures. Biol Reprod 47: 1134-1139.

6) Kuleshova LL, Shaw JM, MacFarlane DR, Trounson AO. 1999. Sugars exert a major influence on the vitrification properties of ethylene glycol-based solutions and have low toxicity to embryos and oocytes. Cryobiology 38:119-130

7) Kuleshova LL, Shaw JM, Trounson AO. 2001. Studies on replacing most of the penetrating cryoprotectant by polymers for embryo cryopreservation. Cryobiology 43: 21-31.

8) Tada N, Sato M, Amann E, Ogawa S. 1993. $A$ simple and rapid method for cryopre-servation of mouse 2-cell embryos by vitrification-beneficial effect of sucrose and raffinose on their cryosurvival rate. Theriogenology 40: 333-344.

9) Saito N, Imai K, Tomizawa M. 1994. Effect of sugars addition on the survival of vitrified 
bovine blastocysts produced in vitro. Theriogenology 41: 1053-1060.

10) Saha $S$, Otoi T, Takagi $M$, Boediono $A$, Sumantri C, Suzuki T. 1996. Normal calves obtained after direct transfer of vitrified bovine embryos using ethylene glycol, trehalose, and polyvinylpyrrolidone. Cryobiology 33: 291-299.

11) Chung HM, Hong SW, Lim JM, Lee SH, Cha WT, Ko JJ, et al. 2000. In vitro blastocyst formation of human oocytes obtained from unstimulated and stimulated cycles after vitrification at various maturational stages. Fertil Steril 73: 545-551.

12) Mukaida $T$, Wada $S$, Takahashi $K$, Pedro $P B$, An TZ, Kasai M. 1998. Vtrification of human embryos based on the assessment of suitable conditions for 8-cell mouse embryos. Hum Reprod 13: 2874-2879.

13) Saito $H$, Ishida GM, Kaneko T, Kawachiya $S$, Ohta N, Takahashi T, Saito T, Hiroi M. 2000. Application of vitrification to human embryo freezing. Gynecol Obstet Invest 49: 145-9.

14) Yokota $Y$, Sato $S$, Yokota $M$, YokotaH, Araki Y. 2001. Birth of a healthy baby following vitrification of human blastocysts. Fertil Steril 75: 1027-9.

15) Kuleshova LL, Lopata A. 2002. Vitrification can be more favorable than slow cooling. Fertil Steril 78: 449-454.

16) Park SE, Son WY, Lee SH et al. 1997. Chromosome and spindle configuration of human oocytes matured in vitro after cryopreservation at the germinal vesicle stage. Fertil Steril 68: 920-926.

17) Johnson MH, Pickering SJ. 1987. The effect of dimethylsulfoxide on the microtubular system of the mouse oocyte. Development 100: 313-324.

18) Carroll J, Depypere H, Matthews CD. 1990. Freeze-thaw-induced changes of the zona pellucida explains decreased rates of fertilization in frozen-thawed mouse oocytes. J Reprod Fertil 90: 547-553.

19) Kuleshova L, Gianoroli L, Magli $C$, et al. 1999. Birth following vitrification of small number of human oocytes. Hum Reprod 14: 3077-3079.

20) Yoon TK, Chung HM, Lim JM, et al. 2000. Pregnancy and delivery of healthy infants developed from vitrified oocytes in a stimulated in vitro fertilization-embryo transfer program. Fertil Steril 74:180-181.

21) Yoon TK, Kim TJ, Park SE, et al. 2003. Livebirth after vitrification of oocytes in a stimulated in vitro fertilization-embryo transfer program. Fertil Steril 79: 1323-1326.

22) Chung HM, Hong SW, Lim JM, et al. 2000. In vitro blastocyst formation of human oocytes obtained from unstimulated and stimulated cycles after vitrification at various maturational stages. Fertil Steril 73: 545-551.

23) Vajta G, Holm P, Kuwayama M, et al. 1998. Open pulled straw (OPS) vitrification: a new way to reduce cryoinjuries of bovine ova and embryos. Mol Reprod Dev 51: 53-58.

24) Lane M, Schoolsraft WB, Gardner DK, et al. 1999. Vitrification of mouse and human blastocysts using a novel cryoloop containerless technique. Fertil Steril 72: 1073-1078.

25) Park SE, Chung HM, Cha KY, et al. 2001. Cryopreservation of ICR mouse oocytes: improved post-thawed preimplantation development after vitrification using Taxol, a cytoskeleton stabilizer. Fertil Steril 75: 1177-1184.

26) Dobrinsky LR, Pursael VG, Long CR, et al. 2000. Birth of piglets after transfer of embryos cryopreserved by cytoskeretal stabilization and vitrification. Biol Reprod 62: 564-570.

27) Isachenko V, Alabart JL, Nawroth F, et al. 2001. The open pulled straw vitrification of ovine GV-oocytes: positive effect of rapid cooling or rapid thawing or both. CryoLett 22:157-62.

28) Stachecki JJ, Cohen J, Willadsen S. 1998. Detrimental effect of sodium during mouse oocytes cryopreservation. Hum Reprod 13: 
395-400.

29) Takahashi $T$, Igarashi $H$, Doshida $M$, et al 2004. Lowering intracellular and extra-cellular calcium contents prevents cytotoxic effects of ethylene glycol-based vitrification solution in unfertilized mouse oocytes. Mol Reprod Dev 68: 250-258. 